\title{
Cisto de inclusão epidérmica em região submandibular em equino: relato de caso
}

Andressa Guidugli Lindquist ${ }^{[a]}$, Polyana Carolina Marino ${ }^{[b]}$, Gustavo Romero Gonçalves ${ }^{[b]}$, Flávia Nesi Maria ${ }^{[c]}$, Caroline Cella Geron ${ }^{[c]}$,Juliana Evangelista Bezerril[ ${ }^{[b]}$

\author{
[a] Universidade Estadual de Londrina (UEL), Londrina, PR, Brasil \\ [b] Centro Universitário Ingá (UNINGÁ), Maringá, PR, Brasil \\ [c] Universidade Estadual do Norte do Paraná (UENP), Bandeirantes, PR, Brasil
}

*Autor correspondente

e-mail: andressaguidugli@icloud.com

\section{Resumo}

O cisto epidermoide, também chamado de cisto de inclusão epidérmica ou cisto folicular, é uma lesão não neoplásica que pode acometer qualquer espécie, sendo mais frequente em cães e bovinos, e raramente em gatos e equinos. Apesar de sua origem congênita, só pode tornar-se evidente quando a esfoliação contínua de células escamosas do seu revestimento epitelial aumenta de tamanho. Foram descritas diferentes regiões de localização, como cabeça, coluna vertebral e nos tecidos presentes no interior do casco, de caráter benigno e localizado. 0 diagnóstico é feito através dos achados macroscópicos e histopatológicos. Foi atendido no Hospital Veterinário da Universidade Estadual do Norte do Paraná, em Bandeirantes, um equino, fêmea, da raça Quarto de Milha, pelagem alazã, com 2 anos de idade, $340 \mathrm{~kg}$, com histórico de aumento de volume na região submandibular direita. 0 animal apresentava esta alteração desde o nascimento, porém, recentemente observou-se aumento no local de forma significativa. Durante o exame físico geral não foram identificadas alterações nos parâmetros clínicos. Contudo, ao exame específico do sistema tegumentar, observou-se um aumento de volume circular de aproximadamente cinco centímetros de diâmetro em terço médio do ramo mandibular direito em região ventral (próximo aos linfonodos submandibulares). Durante a palpação do local, observou-se que sua consistência se apresentava flutuante e, mais internamente, com consistência elástica semelhante a uma "borracha". A conduta inicial foi de punção do local, com auxílio de uma agulha de grosso calibre $(40 \times 12 \mathrm{~mm})$ para excluir a possibilidade de abscesso. Devido ao insucesso do procedimento e permanência do aumento de volume, optou-se por realizar a lancetagem do local com anestesia local e sedação. Após o procedimento, houve saída de secreção acinzentada sebosa, com presença de pêlos em grande quantidade, envoltos por uma cápsula espessa. A partir da identificação do conteúdo e 
visualização minuciosa do mesmo, suspeitou-se de cisto epidermoide, optando-se pelo tratamento cirúrgico para remover todo o conteúdo. Realizou-se uma incisão elíptica ao redor da massa, e a cápsula envolvendo o conteúdo foi removida. 0 conteúdo retirado foi enviado para exame histopatológico, o qual confirmou a suspeita clínica. A remoção cirúrgica é o melhor tratamento, pois as lesões são semelhantes a abscessos, podendo confundir os proprietários dos animais e, como consequência, causar resposta inflamatória local grave na tentativa de remoção. Até o presente momento, poucos trabalhos descreveram a importância dos cistos de inclusão epidérmica como diagnóstico diferencial de lesões nodulares em tecido tegumentar de equinos. Os métodos realizados para este caso e o acesso cirúrgico mostraram-se eficazes, não apresentando recidiva até o momento, podendo ser sugerido para outros casos semelhantes. 0 cisto epidermoide é de ocorrência rara na espécie equina e pouco descrito na literatura, porém quando ocorre não traz prejuízos ao animal, apesar de atrapalhar durante a montaria, colocação de celas, rédeas e, acima de tudo, prejudicar a estética do animal, tornando-se o principal motivo dos proprietários em tentar solucionar o problema o mais rápido possível.

Palavras-chave: Equino. Cisto epidermoide. Lesões nodulares. 